\section{A healthy lifestyle for a healthy heart}

\author{
KATHLEEN KUK
}

Senior Staff Editor

A 1981 study identified no less than 246 coronary "risk factors" that increase a person's chances of suffering a heart attack. Of course, not all of these factors carry equal weight, and not all can be altered. Fortunately, though, most of the risk factors that pose the greatest danger are within your power to control. To significantly reduce your risk of heart attack, follow these vital steps:

\section{Snuff out the smoking habit}

Quitting smoking is the most important way to slash the odds of suffering a heart attack. Smokers have 2 to 4 times the risk of heart attack as nonsmokers, and they are more likely than nonsmokers to die within an hour of heart attack. In addition, smoking interacts strongly with the use of oral contraceptives. A woman smoker who takes birth control pills has 10 times the risk of heart attack as her counterpart without these factors.

You do not need to be a smoker to be gathered into smoking's deadly embrace. Recent findings indicate that the nonsmoking wives of smokers have almost 15 times the incidence of heart attack as women whose husbands also do not smoke. Children who "passively smoke" by breathing in the cigarette smoke of their parents have a higher rate of respiratory infections. The unborn child of a pregnant smoker faces the risk of miscarriage, low- birth weight, complications at delivery, and health problems during infancy.

Smokers may wish to believe that switching to filter cigarettes or to those with less tar and nicotine will help reduce their cardiovascular risk. It won't. In fact, the risk may be greater, perhaps because there is more carbon monoxide in the smoke produced by the filter brands. Also, many smokers take deeper and more frequent puffs on the "safe" cigarettes.

Do not adopt the defeatist attitude that kicking the habit will be too little and too late to do any good. The effects of stopping smoking are almost immediate! One study reveals that within 2 years of kicking the habit, ex-smokers had half the coronary risk of those who continued to smoke. And within 10 years of quitting, the risk of death from heart disease for pack-a-day smokers was almost the same as for those who had never smoked.

\section{Heed high blood pressure}

More than 60 million people have essential hypertension (that is, elevated blood pressure that is not caused by underlying disease). In addition, the prevalence of hypertension increases with age, blacks are twice as likely to have moderate hypertension and three times as likely to have severe hypertension as whites, and persons with hypertension are at twice the risk of developing cardiovascular disease as the rest of the population.

This "silent killer" is easy to ignore because it usually does not generate pain or other symptoms. Indeed, high blood pressure often remains undetected unless a person has his or her blood pressure checked at a physician's office or at a local health fair.

The Joint National Committee on the Detection, 
Evaluation and Treatment of High Blood Pressure defines elevated blood pressure as a systolic pressure greater than 140 and/or a diastolic pressure greater than 90 (written as $140 / 90 \mathrm{~mm}$. $\mathrm{Hg}$ ). Moderate (borderline) hypertension is in the range of $140 / 90$ to $159 / 114 \mathrm{~mm}$. $\mathrm{Hg}$, while severe hypertension is $160 / 115 \mathrm{~mm}$. Hg or greater. A single elevated reading, however, is not conclusive evidence that someone has high blood pressure. Rather, it suggests that further observation and followup is needed.

Although essential hypertension cannot be "cured," it can be controlled through weight reduction, a low-fat/low-salt diet, and exercise. Medication is also prescribed in some cases. Because many people with high blood pressure feel "fine," they sometimes become careless about sticking to their drug regimen. However, missing a pill "here and there" could allow the unseen damage of hypertension to progress. If you are taking high blood pressure medication, you should follow your physician's prescription faithfully. If you are experiencing any side effects, your doctor will change the dosage of the drug, or perhaps substitute with another medication.

\section{Watch that cholesterol!}

Feasting on cholesterol-laden foods such as bacon and eggs, real butter, fried foods, "fast" foods and fatty cuts of meat boosts the levels of cholesterol traveling through the bloodstream. Because the liver produces all of the cholesterol that a body needs to manufacture cell walls, nervous tissue, and vital hormones, any extra amount of cholesterol consumed contributes to atherosclerosis.

Atherosclerosis is a form of "hardening of the arteries" in which excess amounts of cholesterol and other fatty deposits attach themselves to the walls of bloods vessels and narrow the channels. Eventually, the supply of blood to the heart may be completely blocked. When a portion of the heart is starved of vital oxygen and nutrients, chest discomfort or tightness known as "angina pectoris" will develop. An episode of angina pectoris that lasts more than a half hour is more commonly known as a heart attack.

The National Institutes of Health and the American Heart Association have concluded beyond a reasonable doubt that elevated blood cholesterol levels are a major cause of coronary artery disease. The group has set cholesterol goals of 180 milligrams/deciliter (mg./dl.) for persons aged 20 to 29 , and $200 \mathrm{mg} . / \mathrm{dl}$. for those over the age of 30 . At levels above $200 \mathrm{mg} . / \mathrm{dl}$., the risk of heart disease begins to rise sharply. Some physicians suggest an even more conservative cholesterol goal. This target level can be figured by adding one's age to a base cholesterol level of $100 \mathrm{mg} . / \mathrm{dl}$. Thus, a 64year-old would aim for a $164 \mathrm{mg} . / \mathrm{dl}$. cholesterol level.

The NIH also recommends that Americans restrict total dietary fat intake from the present level of $40 \%$ of calories to $30 \%$. Saturated, monounsaturated, and polyunsaturated fats should each account for no more than $10 \%$ of caloric intake, while total cholesterol consumption should be no more than 250-300 mg./day. (For comparison, a single egg yolk contains $252 \mathrm{mg}$. of cholesterol!)

Therefore, disciples of a "healthy heart" diet should skimp on eggs, cream, organ meats (kidney and liver), processed luncheon meats, untrimmed red meat, and foods fried in butter, lard, or fat, and instead eat plenty of fish and poultry, lean meats, fresh fruits and vegetables, sunflower and corn oils, 
and low-fat dairy products. For further tips on how to reduce cholesterol in the diet, look to the January 1987 Patient Health Guide on "Lowering cholesterol levels for better health."

\section{Control diabetes}

Diabetes mellitus is an all-too-common disorder in which the pancreas is unable to produce enough insulin to meet the body's needs. Insulin is the hormone that regulates the levels of glucose, or sugar, in the blood. Without a steady supply of insulin, the cells of the body cannot properly utilize one of their primary sources of fuel.

There are two main types of diabetes mellitus. Insulin-dependent (Type I) diabetes begins primarily in youth. The pancreas produces little or no insulin, so patients must rely upon daily injections of the hormone. Insulin-independent (Type II) diabetes usually does not appear until after the age of 40 . The pancreas generates some insulin, but not enough to meet the body's needs. Often, the middle-aged diabetic eats too much and is overweight. Excess calories and sugar create an even greater burden for the pancreas. Type II diabetes can often be controlled with weight loss, proper diet, exercise, and, when necessary, oral medication. If these methods fail, injections of insulin may be required.

Uncontrolled diabetes eventually plays havoc with the large and small blood vessels. Diabetics have an greater incidence, earlier onset, and increased severity of atherosclerosis, with all of the accompanying risks of stroke, heart attack, and high blood pressure. As a result, 1.5 to 4 times as many diabetics die of cardiovascular disease as nondiabetics, oftentimes without the usual warning signs of chest pain, uncomfortable pressure, nausea, dizziness, or shortness of breath.

Middle-aged individuals or people who are obese and/or have a family history of diabetes should be alert to one or more symptoms of the disease. These include frequent urination, excessive thirst, increased appetite, tiredness or weakness, tingling in the hands and feet, blurred vision, and impotence in men. The symptoms may appear suddenly, within weeks or months, or may take years to emerge. Ignoring these warning signals and thereby delaying diagnosis will permit unseen vascular damage to go undetected and untreated.

Once diagnosed, a diabetic must keep his/her condition under scrupulous control. This means cutting out sugary foods, eating nutritious meals at regular times, keeping track of glucose levels in blood, taking drugs or insulin at prescribed times, and following all doctor's orders. In addition, high blood pressure, obesity, and smoking are taboo. Any of these conditions will worsen a diabetic's health and vastly increase the odds of heart attack and stroke.

The severity and course of diabetes varies greatly. Several visits to a physician, nutritionist, and other experts may be required before the correct individual regimen can be determined.

\section{Take off weight and exercise}

If your favorite exercise is jogging to the nearest fast-food restaurant, you may be overeating and underexercising your way toward a heart attack.

Obesity is considered to be a long-term predictor for heart disease, because blood is diverted away from the heart to meet the needs of the extra bulk. This blood supply to the heart will be further depleted during exercise or stressful situations, thereby increasing the risk of angina pectoris. An unhealthy lifestyle-a high-fat/high-cholesterol diet and a lack of exercise, for instance-has probably contributed to this hefty state. Life insurance companies have taken the weight factor into consideration and have decided, for example, that a woman who is $100 \%$ over desired weight has a $21 / 2$-fold excess risk for cardiovascular disease.

Obesity's greatest impact on heart disease is additive, in that it magnifies the strength of other risk factors, including diabetes, hypertension, high cholesterol levels, and other health problems.

A sensible weight-loss plan is aimed at decreasing caloric intake while establishing a new pattern of eating that will last a lifetime. One fine example is the American Diabetes and American Dietetic 
Associations' Exchange lists. This diet has proved successful with diabetic and nondiabetic dieters alike. The basic meal plan consists of 6 food groups-milk, vegetable, fruit, bread, meat, and fat- that can be mixed and matched to fulfill the daily requirements of calories and nutrients. In addition, the American Heart Association has published a cookbook that features good-tasting, low-cholesterol recipes. (The Exchange lists can be obtained for a nominal charge from a local ADA affiliate, while the AHA Cookbook can be picked up at any local bookstore.) A physician or dietician may have other, personalized recommendations for your new diet. Consult with these professionals before launching into any new plan, especially if you have special health needs that must be met.

The ideal complement to diet is exercise. It burns up excess calories, improves body shape and self-esteem, serves as an outlet for stress, improves the efficiency of heart and lungs, and increases stamina. And even though physical inactivity is not a strong, independent link to heart disease, several studies - as well as common observation-suggest that inactive men and women run a higher risk of heart attack than their energetic colleagues.

The best exercise program has 3 key conponents. It must be a brisk workout that raises heart and breathing rates, it must be sustained for at least 15 to 30 minutes without interruption, and it must be regularly repeated at least 3 times a week. In addition, each activity has 3 phases - the warm-up, the workout, and the cool-down. Good exercises include brisk walking, cycling, jogging, swimming, "jazzercise," racquet sports, jumping rope, and plain ole' calisthenics.

It is best not to jump recklessly into a new regimen. A body that took years to fall out of shape cannot be transformed overnight. Set a goal and build up to it gradually. You should also consult a physician before embarking on a fitness program, particularly if you are more than moderately overweight, if you smoke, and/or if you have diabetes, high blood pressure, or a family history of heart disease. In this case, exercise probably will not be ruled out-it will just be tailored to individual needs.

\section{Relax}

Stress-whether it be driving in rush-hour traffic, preparing to give a speech, or working against deadline-is a necessary fact of life. Without it, life would be pretty boring. The human body has adapted a "fight-or-flight" mechanism to help us adapt to stressful events. A boost of the hormone adrenaline quickens breathing and heart rates, turns the stomach queasy, tenses the muscles, and raises blood pressure. This response is fine....as long as there is a release. Scientists have determined that the body may be harmed if a person is under a constant state of stress. For example, air traffic controllers have a higher rate of hypertension than workers in less tense occupations. And residents living in noisy, high-traffic neighborhoods tend to have higher blood pressure than dwellers of more peaceful hamlets.

It is difficult to measure a correct amount of pressure or stress because each person reacts differently. However, researchers have classified people into two lifestyle groups that may influence a person's risk of heart attack. Type A individuals are described as being bossy, hostile, time- and deadline-conscious, aggressive, and excessively competitive. Type B persons are more "laid back," agreeable, and patient. Not too surprisingly, type A individuals have been dubbed "coronary prone," because their incidence of coronary heart disease was almost double that of more relaxed persons in one scientific study.

Lifestyles are not easy to change. And the order to do so may be more stressful than the original condition. In any case, everyone can practice some simple steps to reduce tension in their lives. Exercise is a good way to release pent-up frustrations. Relaxation techniques will release physical knots and mental kinks at the end of a hard day. (One such technique requires the person to stretch out on the floor. Then, area by area, he or she squeezes and relaxes the muscles of the face, shoulders, arms, fingertips, buttocks, legs, and toes. The body will literally be relaxed from head 
to toe!) Hobbies offer a needed diversion. Such activities as volunteer work, social groups, and religious involvement will create a new circle of friends and experiences and help to release excess energy.

\section{The unavoidable risk factors}

Age, family history, gender, and race are cardiac risk factors that are totally beyond anyone's control.

Age is the strongest cardiovascular risk factor. Fifty-five percent of all heart attack victims are over the age of 65 . Of all victims who die, 4 of 5 are over 65. Hypertension and diabetes, two major conditions that contribute to heart attack, also become more common in the advancing years.

Cardiac disease has a genetic link and tends to run in the family. The incidence of heart attack jumps 2 to 4 times in first-degree relatives of persons who have themselves suffered a heart attack. We cannot restock the family tree, but we can work with the knowledge of our heredity and be forewarned. A person whose father died of a heart attack at 54 is tempting fate if he or she does not stop smoking, lose excess pounds, and eat properly. This person should also have regular check-ups to monitor blood pressure, cholesterol, and blood sugar levels.

It has been said that in the battle of the sexes, men hold numerous advantages over women. However, a healthy heart is not one of them. Males run a greater risk of heart attack than females, perhaps because of a protective effect of female hormones. Although the incidence of heart attack increases in women after menopause, a large gap still exists between the sexes.

As mentioned before, blacks are more prone to cardiovascular disease than whites. This imbalance can be traced to the greater incidence of hypertension in black Americans. Therefore, it is of the utmost importance for blacks to have their blood pressure strictly monitored, even if they feel terrific.
The risk factors for stroke and heart attack are similar and overlapping. Although this article has outlined how to reduce the chances of suffering a heart attack, the benefits of not smoking, losing weight, getting plenty of exercise, reducing cholesterol intake, and controlling high blood pressure and diabetes are good for anybody, anytime.

(All material in the Patient Health Guide is reviewed by JAOA referees.)

\section{References}

Exercise and your heart. By the National Heart, Lung and Blood Institute, National Institutes of Health, Bethesda, Maryland 1981.

Identification and relative weight of cardiovascular risk factors. By P.N. Hopkins and R.R. Williams. Cardiology Clinics, vol. 4, pp. 3-22, Feb 1986

Lowering cholesterol levels for better health. By K. Kuk. Journal of the American Osteopathic Association, vol. 87, pp. 93-7, Jan 1987

1984 Report of the Joint National Committee on Detection, Evaluation and Treatment of High Blood Pressure. Journal of the American Osteopathic Association, vol. 83, pp. 642-58, May 1984

1986 Heart Facts. By the American Heart Association, Dallas, Texas 1985

Preventive cardiology for coronary artery disease. By W.W. Miller. Primary Care, vol. 12, pp. 15-38, Mar 1985

Risks for arterial hypertension. By R.E. Schmieder, F.H. Messerli, and H. Ruddel. Cardiology Clinics, vol. 4, pp. 57-66, Feb 1986

Risks for glucose intolerance. By L.J. Klaff and J.P Palmer. Cardiology Clinics, vol. 4, pp. 67-73, Feb 1986

Risks for obesity. By C. Amodeo and F.H. Messerli. Cardiology Clinics, vol. 4, pp. 75-8, Feb 1986

Why risk heart attack? Seven ways to guard your heart. By the American Heart Association, Dallas Texas, 1981 


\section{BIBLIOTHERAPY FOR A HEALTHY HEART}

Eager to learn more about ways to reduce your risk of heart attack? The following list of materials is a good place to continue your search. Books can be obtained from a local library or a bookstore. When writing for pamphlets, include a self-addressed, stamped envelope. National associations are ready and willing to assist you. However, you will get a quicker response by contacting your local affiliate.

\section{BOOKS}

The American Medical Association Book: Heartcare. By the American Medical Association, Random House, New York, 1982.

The American Heart Association Heartbook: A Guide to Prevention and Treatment of Cardiovascular Diseases.

Dutton Press, New York, 1980.

Coronary Heart Disease: The Facts. By J.P. Shillingford. Oxford Press, New York, 1982.

Exercise and Your Heart. U.S. Department of Health \& Human Services, Washington D.C., 1981.

The Healthy Heart. By A. Fisher. Time-Life Books, Alexandria, VA 1981.

Heart Attack. By E.K. Chung. Appleton-Century-Crofts, Norwalk, CT, 1982.

The Human Heart: A Consumer's Guide to Cardiac Care. By B. Phibbs. Mosby Press, St. Louis, MO, 1982.

The Living Heart Diet. By S. Heyden, et al. Raven Press, New York, 1982.

Love Your Heart. By L. Belshin and D.T. Mason.

International Dialogue Press, Davis, CA 1982.

One Heart...One life: A Healthy Heart Handbook. By E. Chung. Prentice-Hall, Englewood Cliffs, NJ, 1982.
Prevent Your Heart Attack. By N. Kaplan. Scribner Press, New York, 1983.

Take Care of Your Heart. By E. Amsterdam and A. Holmes. Facts on File Publications, New York, 1983.

Your Healthy Heart: The Family Guide to Staying Healthy and Living Longer. By C. Barnard and P. Evens. McGraw Publishers, New York, 1984.

Your Heart and Blood (juvenile). By L.J. LeMaster. Children's Press, Chicago, 1984.

\section{BOOKLETS}

American Heart Association 7320 Greenville Avenue

Dallas, TX 75231

Cholesterol and Your Heart, Nutrition for the Fitness Challenge, The Heart and Blood Vessels, Smoking and Heart Disease, Why Risk Heart Attack: Seven Ways to Guard Your Heart, Recipes for Fat-Controlled Low Cholesterol Meals, High Blood Pressure: Facts You Need to Know, and many, many more booklets. Several pamphlets also available in Spanish. Contact the national headquarters or your local affiliate.

American Lung Association

1740 Broadway

New York, NY 10019 


\section{BIBLIOTHERAPY FOR A HEALTHY HEART}

Freedom From Smoking in 20 Days, A Lifetime of Freedom From Smoking, Second-Hand Smoke, and other booklets on the risks of smoking. Contact the national headquarters or your local affiliate.

\section{American Cancer Society}

\section{Park Avenue}

New York, NY 10016

Quitter's Guide: 7 Day Plan to Help Your Stop Smoking Cigarettes, and other pamphlets on smoking cessation. Contact the national headquarters or your local affiliate.

National Heart, Lung, and Blood Institute

National Institutes of Health

Building 31, Room 4A-21

Bethesda, MD 20205

Medicine for the Layman Series: Arteriosclerosis, Heart Attacks (no. 81-1803), How Doctor's Diagnose Heart Disease (no. 81-752, Spanish version no. 78-1009), Facts about Cholesterol, Questions about Weight, Salt, and High Blood Pressure (no. 82-1459), Exercise and Your Heart (no. 81-1677), and Diabetes and Cardiovascular Disease.

Consumer Information Center

P.O. Box 100

Pueblo, Colorado 81002

Diet, Exercise and Other Keys to a Healthy Heart (607P), Clearing the Air: A Guide to Quitting Smoking (561P), A Compendium of Fats (515P), Nurtrition and Your Health:
Dietary Guidelines for Americans (520P), Sodium (523P), Calories and Weight (120P, \$2.25), Fitness Fundamentals (121P, \$1.00), Walking for Fitness and Pleasure (122P, $\$ 1.00$ ), Protect Your Lifeline: Fight High Blood Pressure (124P, \$2.00). Free unless indicated. Include a $\$ 1.00$ fee when ordering 2 or more free booklets.

High Blood Pressure Information Center $120 / 80$

National Institutes of Health

Bethesda, MD 20205

Blacks and High Blood Pressure (no. 80-2024), High Blood Pressure and What You Can Do About It ( no. 84-1218), High Blood Pressure Facts and Fiction (no. 84-1218, also in Spanish).

National Health Information Clearinghouse P.O. Box 1133

Washington, D.C. 20013-1133

Nutrition and Your Health: Dietary Guidelines for Americans (no. 001-000-04248-3, also in Spanish).

Food And Drug Administration Office of Consumer Affairs

Public Inquiries

5600 Fishers Lane

Rockville, MD 20857

On Being Too Rich, Too Thin, and Too Cholesterol Laden (no. 81-1087), Primer on Three Nutrients-Proteins, Carbohydrates, and Fats (no. 81-2026). 


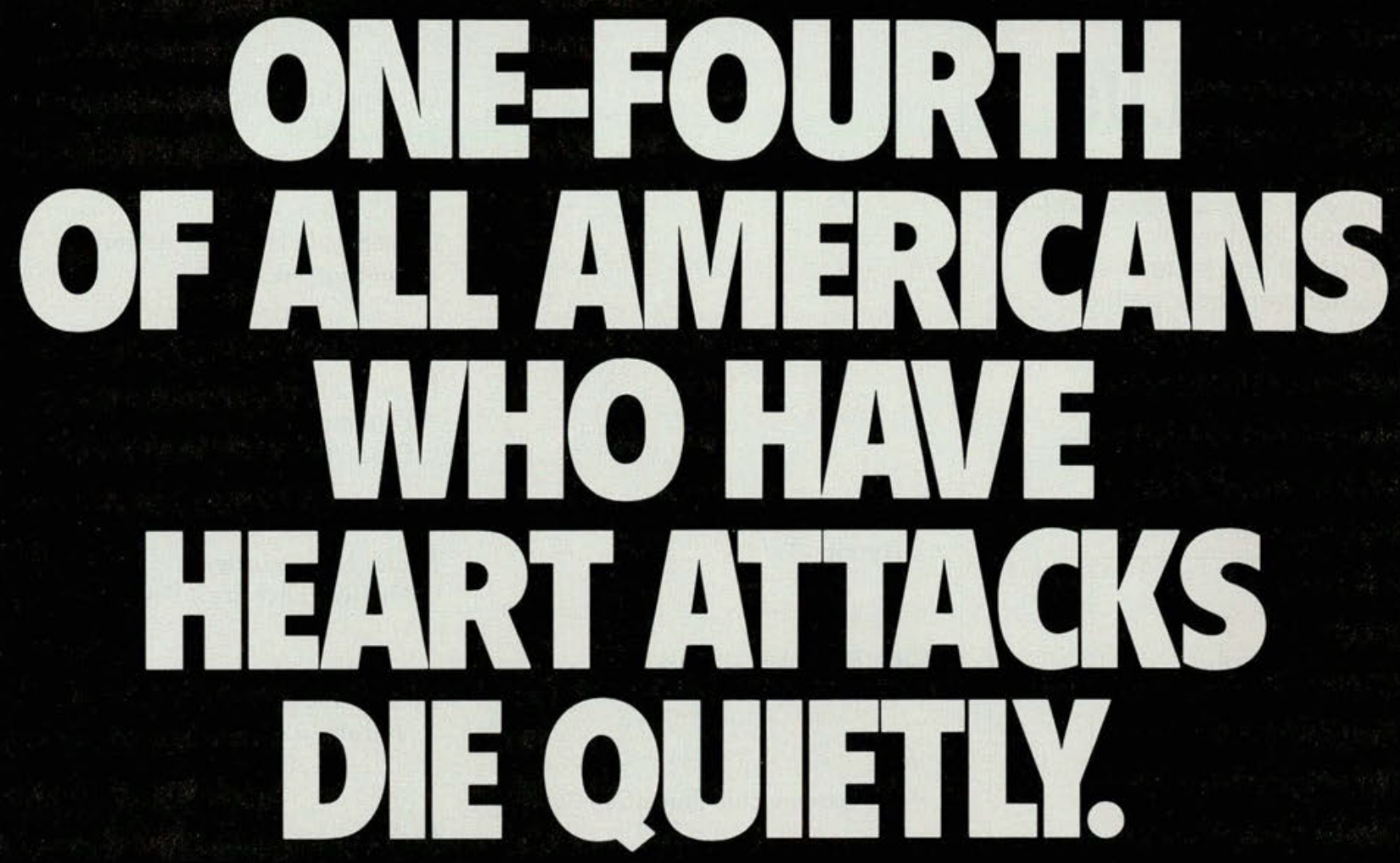

They tell themselves it's indigestion. Or that they're too young to be having a heart attack. Or too healthy. They wait an average of three hours before they even think about calling for help.

If you experience pressure, fullness, squeezing or pain in the center of your chest that lasts two minutes - or pain that spreads to your shoulders, neck or arms - or dizziness, fainting, sweating, nausea or shortness of breath - call the emergency medical service.

Speak now. Or forever hold your peace. 